\title{
A co-incineração de resíduos perigosos
}

\author{
SEB A S T I A O J. FOR MOS I N H O *
}

\section{Gestão de resíduos}

Os resíduos da actividade humana e industrial classificados como perigosos, são-no em relação ao seu possível abandono no meio que nos rodeia, sólido ou líquido ou mesmo queimados em condições não-controladas ${ }^{1}$. Em tais condições contaminam as águas, os solos e o ar e, deste modo, causam prejuízos apreciáveis à saúde pública e ao ambiente. É para evitar tais riscos significativos que os governos e as sociedades adoptam várias técnicas de gestão de resíduos que, em essência, procuram mitigar os perigos e prejuizos que tais resíduos podem causar à saúde pública e ao ambiente. Este desiderato pode ser alcançado pelo recurso a tratamentos controlados por métodos físicos, químicos, biológicos ou térmicos que tornem as substâncias mais inócuas ou as destruam, seguido pelo confinamento, ou pela dispersão, ou por uma colocação final dos produtos sólidos resultantes de tais tratamentos.

Preferencialmente, há que evitar a produção dos próprios resíduos, ou quando sejam produzidos que venham a constituir fonte de matérias primas para outras indústrias (emissão zero). Em alternativa, de menor hierarquia que a prevenção ou "emissão zero", os resíduos podem ser reciclados ou re-utilizados, mas tais processos geram por si mesmos novos resíduos que tem de ser colocados nos ciclos de tratamento acima referidos.

Dada a grande variedade de características físicas e químicas dos resíduos perigosos, as tecnologias de gestão têm de ser escolhidas criteriosamente para cada tipo de resíduo, atendendo à natureza físico-química dos próprios resíduos, ao seu grau de periculosidade, à extensão de tratamento requerida e a factores económicos de sustentabilidade social e industrial ${ }^{2}$. As tecnologias de tratamento correntes podem ser divididas em quatros grandes classes (processos físicos, físico-químicos e químicos, biológicos e térmicos), para além da disposição final em aterro.

As políticas ambientais dos países e da União Europeia têm como grande objectivo a saúde pública, quer numa escala nacional, regional ou local. As decisões políticas incidem sobre os perigos (prejuízos potenciais) e os riscos (prejuizos prováveis) ambientais. A complexidade do sistemas físicos e biológicos torna difícil estabelecer uma correlação de causa-efeito sobre os efeitos da poluição na saúde pública. A Agência Europeia do Ambiente estima que as "agressões ambientais" contribuem em cerca de $5 \%$ para as doenças, efeito esse que cresce para $12 \%$ com os acidentes de trânsito e domésticos. Os efeitos mais significativos provém das partículas na atmosfera e seguidamente dos efeitos de dióxido de enxofre e de ozono; o efeito de $\mathrm{SO}_{2}$ decresceu acentuadamente na última década ${ }^{3}$.

A contaminação dos solos constitui tema de preocupação na Europa. Neste continente existem centenas de milha-

figura 1 Perfis térmicos e tempos de residência na fase gasosa (_-) e para a matéria prima e clinquer (......) numa unidade cimenteira (adaptado da ref. 16).

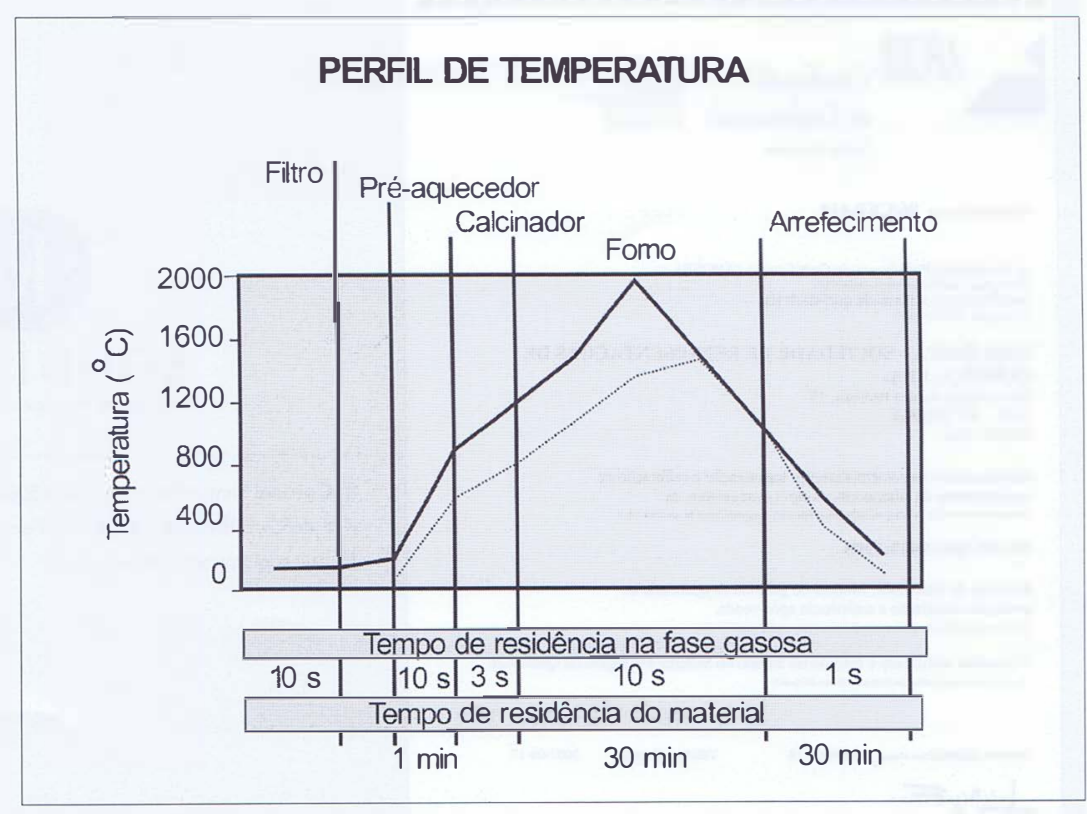


res de locais contaminados por metais e substâncias orgânicas tóxicas, mormente as lipofilicas onde figuram os organoclorados. Nestes locais figuram também os provenientes de aterros mais antigos, ao tempo sem o devido controlo ${ }^{4}$.

A maior contaminação das águas superficiais e subterrâneas provém de pesticidas; cerca de 80 substâncias para uma contaminação moderada em águas superficiais e 25 substâncias em águas subterrâneas. $O$ pesticida que mais frequentemente excede o limite legal $(0,1$ $\mu \mathrm{g} / \mathrm{p}$ para um só pesticida) é a atrazina. Suscitam igualmente alguma preocupação os fertilizantes à base de fosfato de cádmio. Mas de um modo geral, a poluição aquática tem decrescido por toda a União Europeia.

No que concerne aos processos de incineração, não foi possível detectar algum impacto resultante de pequenos acréscimos adicionais da exposição a poluentes de incineradoras ${ }^{5}$. O ruído excessivo afecta não só a saúde e a qualidade de vida, como também o comportamento social e o desenvolvimento cognitivo.

\section{Destruição térmica de resíduos}

O tema deste trabalho diz respeito ao tratamento de destruição térmica de resíduos que não são passíveis de outros métodos de gestão e, neste domínio, iremos abordar os processos de coincineração. Os resíduos banais ou perigosos $^{6}$ são constituídos por compostos orgânicos e por metais. Dado que os elementos metálicos não são passíveis de destruição, a destruição térmica equivale à destruição dos compostos orgânicos que constituem os próprios resíduos. Em meios com excesso de oxigénio, a combustão leva, idealmente, à transformação de todos os compostos orgânicos em $\mathrm{CO}_{2}$ e $\mathrm{H}_{2} \mathrm{O}$. Há alternativas de destruição térmica por pirólise, em meios com ausência de oxigénio. Contudo, abordaremos apenas os primeiros que dizem respeito aos processos de co-incineração em unidades cimenteiras, o objecto deste artigo.

No passado, a destruição térmica de resíduos era operada somente em for- nos de incineradoras dedicadas. Apesar de construídas para esta finalidade, isto não as volve, necessariamente, no melhor sistema de destruição térmica para qualquer tipo de resíduo. Trata-se de incineradoras-dedicadas generalistas. A lei obriga a que os seus fornos alcancem uma temperatura máxima de $850^{\circ} \mathrm{C}\left(1100^{\circ} \mathrm{C}\right.$ para compostos clorados ou halogenados) a um mínimo de $6 \%$ de oxigénio, e que o tempo de residência dos compostos na fase gasosa seja pelo menos de 2s. Porém, operam na indústria química incineradoras especializadas em queima de resíduos altamente contaminados em certas classes de substâncias: compostos de cloro ou de enxofre ou de bromo, etc. Tais incineradoras especiais podem ser utilizadas para a destruição térmica de resíduos industriais perigosos (RIP) muito contaminados, provenientes de diversas indústrias. Todos estes tipos de incineradoras, porque não destroem os compostos orgânicos com uma eficiência de 99,99\% em geral e 99,9999\% para dioxinas/furanos (adiante designados abreviadamente por dioxinas), carecem de um sistema de lavagem dos gases de emissão. Lavagem através, por exemplo, de leite de cal para ácidos, como $\mathrm{HCl}, \mathrm{HF}$ e $\mathrm{SO}_{2}$, de carvão activado para adsorver e remover dioxinas, aromáticos policíclicos, mercúrio e outros metais pesados, etc. Deste modo alcançam os índices legais de destruição e remoção de 99,9999\% para dioxinas, mas conduzem à formação de resíduos de cinzas altamente contaminadas para além de escórias de metais pesados e cinzas formadas directamente na incineradora e recolhidas no fundo do forno por escorrimento, que têm de ser confinados e incorporados através de reacções de hidratação em massa de cimento ou de betão ou em meios sólidos de vitrificação, antes de serem colocados em aterros de resíduos industriais perigosos.

\section{Co-incineração em fornos de unidades cimenteiras}

A destruição térmica de resíduos não excessivamente contaminados pode ser operada. muitas vezes com vantagens, em fornos de outras unidades industriais que foram adaptados para a queima de resíduos como combustível alternativo, sem deixaram de operar no destino para que foram concebidos. Este método designado por co-incineração pode ser operado em fornos de unidades cimenteiras, fornos de cal, siderurgias, vidreiras, centrais térmicas, etc. Os mais populares são os fornos de cimenteiras para a produção de clinquer, porque têm uma lavagem de gases de emissão ácidos, $\mathrm{HCl}$ e $\mathrm{HF}$ e mesmo $\mathrm{SO}_{2}$, pelo pó da matéria prima que é alcalina. Acresce que os fornos são protegidos por tijolos refractários e bastante resistentes à corrosão, o que não se verifica com outras indústrias atrás mencionadas, por exemplo, as centrais térmicas. 0 perfil de temperatura na instalação de uma cimenteira, por via seca, no calcinador e no forno para a sinterização da matéria prima é tão elevado (ver Figura 1) que, quando os resíduos perigosos são adicionados ao queimador principal, conduz a tempos de residência na fase gasosa de cerca de 4-6s a uma temperatura superior a $1200{ }^{\circ} \mathrm{C}$ em atmosfera oxidante. Não surpreenderá, pois, que os índices de destruição da matéria orgânica suplantem os limites legais de 99,99\%. No que diz respeito às dioxinas são destruídas quase completamente no forno, e as que são emitidas resultam da formação de novo nos gases de escape e o seu baixíssimo valor (na gama dos décimos de $\mathrm{ng} / \mathrm{Nm}^{3}$ ) só depende da temperatura nos despoeiradores, sendo tanto mais baixo quanto mais baixa for a temperatura ${ }^{7}$. Assim, os valores de 99,9999\% são alcançados sem qualquer sistema de adição de carvão activado aos gases emitidos pela chaminé

Durante muito tempo admitiu-se que, numa perspectiva ambiental, o processo de co-incineração da generalidade de RIP em cimenteiras era inferior ao das incineradoras dedicadas. Contudo, a partir dos meados da década de 90 começaram a surgir Análises de Ciclo de Vida (ACV) apontando todas no sentido de que a co-incineração de RIP em cimenteiras é mais amiga do ambiente que a queima em incineradoras dedica$\mathrm{das}^{8}$. As ACV constituem a única meto- 
dologia que aborda o impacto ambiental de qualquer actividade humana ou industrial, de uma forma integrada, entrando em conta com todos os efeitos sobre o ambiente. A Tabela 1 apresenta, a título de exemplo, um resumo comparativo do desempenho ambiental da co-incineração e da incineração dedicada para a queima de lamas de tintas. Os piores impactos ambientais da incineração dedicada são essencialmente fruto da formação de cinzas e escórias contaminadas, o que não se verifica na co-incineração em cimenteiras que não produzem tais residuos adicionais. A necessidade de colocar as cinzas e escórias da incineração dedicada em aterros industriais perigosos tem um impacto muito mau para o ambiente, porque tais aterros podem necessitar de controlo por algumas centenas de anos, ${ }^{9}$ pelo que só devem ser utilizados quando não há solução alternativa. Não constituem uma eterna preocupação ambiental para o futuro como são os

\section{Impacto ambiental Incineração dedicada Co-incineração em cimenteiras}

\begin{tabular}{lcc}
\hline $\begin{array}{l}\text { Impacto directo } \\
\text { no ambiente }\end{array}$ & 2 & $-19,2$ \\
\hline $\begin{array}{l}\text { Impacto dos residuos } \\
\text { gerados ou evitados }\end{array}$ & 333,5 & $-0,2$ \\
\hline Impacto total & 335,5 & $-19,4$ \\
\hline
\end{tabular}

tabela 1 Estudo ACV comparativo para a queima de lamas de tintas em incineradoras dedicadas e por co-incineração em cimenteiras (valores negativos indicam beneficios para o ambiente). ${ }^{10}$

resíduos radioactivos, mas algo que equivaleria a um permanente controlo ambiental desde o tempo de D. Sebastião até aos nossos dias.

A componente inorgânica dos RIP constituída por metais pesados, vai ser incorporada no clinquer. As recomendaçōes nacionais para a co-incineração de RIP ${ }^{11}$ em cimenteiras colocam limites de concentrações de diferentes metais à entrada do forno de modo a não exceder no total $0,015 \%$, pelo que a composição dos cimentos formados na co-incineração não será diferente da gama de variação em metais pesados dos cimentos comerciais preparados com com- mesma gama encontrada em rochas, solos e argilas, e com uma média (45 ppm) um pouco inferior ao verificado nos cimentos em 1994 (60 ppm), apesar de durante este intervalo de tempo o uso de combustiveis alternativos ter praticamente duplicado: 10\% em 1994 e 19\% em 1998. O pequeno decréscimo verificado pode ser devido, em parte, a alterações no tipo dos tijolos utilizados para o revestimento dos fornos. Os testes de lixiviação de metais pesados em cimentos alemães têm dado valores consistentemente inferiores aos requeridos para a água de abastecimento público, que é o produto de consumo público alimentar com legislação mais apertada e com maior frequência de análises químicas e bateriológicas.

Atendendo às restrições em metais pesados e compostos halogenados presentes nos RIP cujo método de tratamento recomendado é a destruição térmica, 95\% dos RIP nacionais podem ser destruídos por co-incineração em fornos de unidades cimenteiras ${ }^{13}$

\section{Destruição de compostos orgânicos em co-incineração}

Embora nem todos os resíduos contendo matéria orgânica sejam admitidos à co-incineração em cimenteiras, mesmo assim há uma grande variedade de substâncias orgânicas que carecem de ser destruídas a 99,99\% no interior dos fornos. Para garantir este desiderato recorre-se às Tabelas de Dellinger ${ }^{14}$ que ordenam cerca de 320 moléculas em ordem decrescente de facilidade de destruição térmica, quer em combustão quer em pirólise. Algumas destas moléculas podem ser utilizados nos ensaios iniciais (trial burn) de queima de RIP pré-tratados para a optimização do processo, de modo a destruir as moléculas orgânicas a mais de 99,99\%. Geralmente escolhe-se uma molécula no topo da lista, por ser de destruição térmica mais difícil (Principal Organic Hazardous Constituents $(\mathrm{POHC})$ ). Garantida a destruição deste traçador, está garantida a destruição de todas as moléculas orgânicas em posição inferior na Tabela. Contudo, algumas das moléculas do topo são venenosas como o ácido cianídrico, cancerígenas como o benzeno ou difíceis de detectar como o acetonitrilo. Uma hipótese aceitável poderia ser, por exemplo, o tolueno que figura somente em 35..$^{\circ}$ lugar na lista de Dellinger. Mas a questão que se coloca neste enquadramento é a de se se poderá testar a destruição do tolueno em condiçōes equivalentes às do topo da tabela?

Como a Figura 2 ilustra para um grupo seleccionado de moléculas orgânicas (benzeno e derivados monossubstituídos), verifica-se que há uma correlação entre a posição, $p$, da molécula e a energia de ligação média, $E_{b, m}$, em cada molécula, 


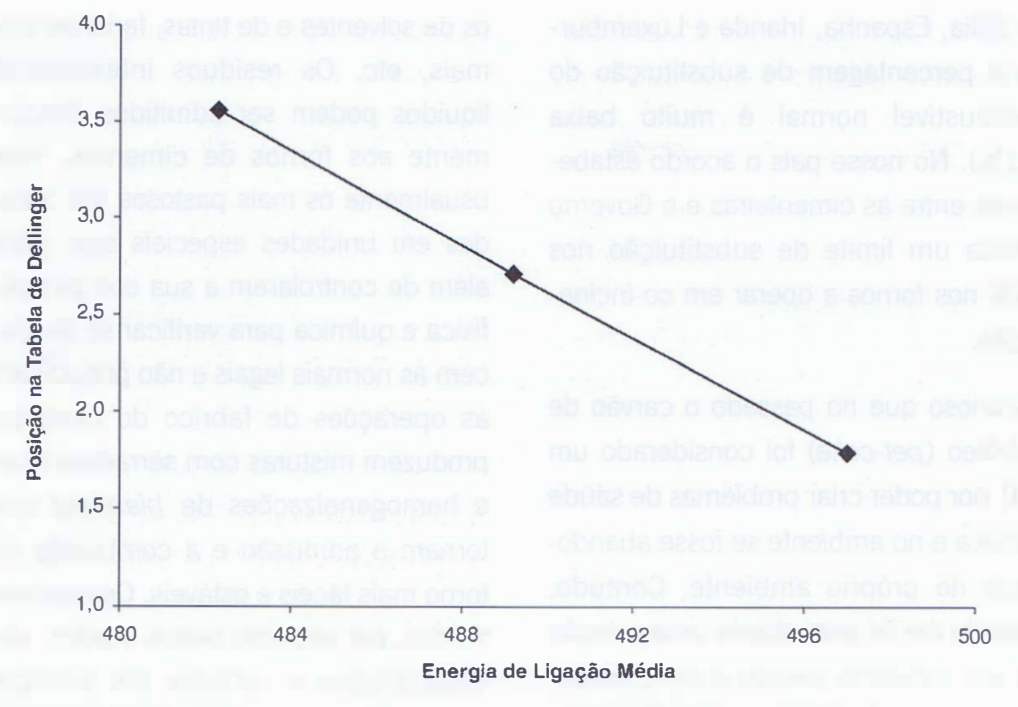

figura 2 Correlação entre o logaritmo da posição (p) dos Constituintes Perigosos Orgânicos Principais (POHC, Principal Organic Hazardous Constituentes) em resíduos industriais e a energia média das respectivas ligações químicas, $E_{b, m}$

$$
\ln p=-0,12 E_{b, m}+61,43
$$

Desta equação se extrapola que $E_{b, m}$ para a molécula de mais difícil destruição térmica, $p=1$, será $E_{b, m}=512 \mathrm{~kJ} / \mathrm{mol}$. Esta correlação aponta para algum tipo de associação entre a posição da molécula na Tabela de Dellinger e a sua aparente energia de activação, $E_{a}$, para a destruição.

Modelos de reactividade química ${ }^{15}$, como a teoria de Marcus e o Modelo de Intersecção de Estados, que representam as reacções em termos do cruzamento de duas curvas de energia potencial, uma para reagentes e outra para produtos, contemplam o efeito da energia de reacção, $\Delta E^{0}$, na energia de activação, $E_{a}$. Este efeito é traduzido pelo coeficiente de Brönsted, $\alpha$, que no caso de curvas potenciais iguais assume o valor $\alpha=1 / 2$. Admitindo que esta aproximação é aceitável no caso em apreço, podemos escrever

$$
E_{a} \propto \alpha \Delta E^{o} \propto\left\{\left(E_{b, m}(1)-E_{b, m}(35)\right\}\right.
$$

Da eq.(2) e com $E_{b, m}=482 \mathrm{~kJ} / \mathrm{mol}$ para o tolueno, vem $\Delta E_{a}=E_{a}(1)-E_{a}(35)=$ $15 \mathrm{~kJ} / \mathrm{mol}$ entre a molécula de destruição térmica mais difícil e o tolueno. Sabendo que a constante de velocidade de reacção, $k$, é dada pela equação de Arrhenius,

$$
k \propto e^{\frac{E_{a}}{R T}}
$$

a uma temperatura média de $1200{ }^{\circ} \mathrm{C}$, estima-se que o tolueno seria 3,4 vezes mais destruído que a molécula de $p=1$ e, consequentemente, que se deveria requer uma destruição do tolueno de 99,997\% para garantir a destruição de toda a classe de moléculas orgânicas presentes nos resíduos.

\section{Panorama europeu sobre a utilização de RIP como combustíveis alternativos em cimenteiras}

Nos primórdios da co-incineração em cimenteiras foram cometidos erros. Nos Estados Unidos, ao contrário do panorama europeu, muitas cimenteiras operam por via húmida. Os processos de homogeneização de sólidos em líquidos ou de líquidos em líquidos são muito mais fáceis do que o de sólidos em sólidos requerido pela produção de cimento por via seca. Contudo, na via húmida a homogeneização da pasta é realizada em tanques com alguma água e, por isso, muito maleável à adição à matéria prima de uma gama muito diferenciada de resíduos. A matéria prima, assim preparada, é adicionada à parte fixa do forno rotativo, zona fria, quase à temperatura ambiente, não havendo qualquer torre de ciclones. Daí os resíduos serem colocados directamente no início do forno, e dado que este funciona com uma contra-corrente de ar, os residuos eram parcialmente arrastados para fora da zona de combustão muito antes de terem alcançado zonas de temperatura elevada. Sofriam uma combustão incompleta e produziram dioxinas em quantidades significativas.

Todo este procedimento foi modificado. Primeiro, pelo pré-tratamento que através de misturas físicas converte os RIP num combustivel alternativo adaptado a um funcionamento estável de cada forno. Segundo, pela sua admissão junto a queimador principal que é a zona de temperatura mais elevada do forno. Terceiro, pela admissão do RIP pré-tratado somente quando o forno está estabilizado.

A respeito da emissão de dioxinas, no panorama da indústria cimenteira americana há ainda mais dois factores que a desfavorecem em relação à europeia. 0 primeiro é a elevada temperatura dos electrofiltros, cerca de $400{ }^{\circ} \mathrm{C}$, por contraste com a situação das cimenteiras europeias que trabalham todas com electrofiltros a temperaturas $<200{ }^{\circ} \mathrm{C} \mathrm{e}$, por isso, com emissōes de dioxinas muito inferiores. Finalmente, dado que os Estados Unidos são ricos em petróleo, é natural que as matérias primas para as suas cimenteiras sejam muito mais ricas em matéria orgânica, o que também contribui para uma maior emissão de dioxinas durante o processo de fabrico do cimento com ou sem combustíveis alternativos. Assim se compreende que os limites legais para a emissão de dioxinas sejam de 0,1 ng I-TEQ/Nm ${ }^{3}$ na UE e de 0,2 ng I$\mathrm{TEQ} / \mathrm{Nm}^{3}$ nos EUA

Há cerca de uma década a co-incineração de resíduos é praticada extensivamente e de forma segura em doze países da União Europeia, nos Estados Unidos, no Japão e na Suiça, funcionando os resíduos pré-tratados como combustível alternativo. Há pois uma valorização energética dos resíduos que se tornou mais premente após a $2 .^{\text {a }}$ crise petrolifera, mormente numa indústria de elevado consumo energético como é a indústria cimenteira. A nível da UE, cerca de 150 fornos dos 450 existentes em 250 unidades cimenteiras 
recorrem a combustiveis alternativos num total de material equivalente a cerca de 3 milhões de toneladas de carvão por ano, o que corresponde, em média, à substituição de combustível normal em $20 \%$; espera-se que nos próximos anos este quantitativo aumente para o dobro ${ }^{16}$. Na Alemanha todas as cimenteiras operam em co-incineração e em países desenvolvidos como a Alemanha, Áustria, Bélgica e França o combustível alternativo chega a ultrapassar os $50 \%$ dos combustiveis normais, carvão e pet-coke (cerca de $40 \%$ cada), fuel e gás natural. Em França a co-incineração cresce a um ritmo de $5 \%$ ao ano, tendo a sua evolução entre 1989 e 1999 correspondido a um acréscimo de 84\%; a incineração dedicada estabilizou neste período. Por contraste, na Itália, Espanha, Irlanda e Luxemburgo a percentagem de substituição do combustivel normal é muito baixa $(<1 \%)$. No nosso país o acordo estabelecido entre as cimenteiras e o Governo coloca um limite de substituição nos $25 \%$ nos fornos a operar em co-incineração.

É curioso que no passado o carvão de petróleo (pet-coke) foi considerado um RIP, por poder criar problemas de saúde pública e no ambiente se fosse abandonado no próprio ambiente. Contudo, quando Ihe foi encontrada uma solução de uso industrial passou a ser considerado um combustível normal. Presentemente, os RIP utilizados em cimenteiras são óleos usados, lubrificantes, resíduos de plásticos, resíduos de papel, resídu- os de solventes e de tintas, farinhas animais, etc. Os resíduos inteiramente líquidos podem ser admitidos directamente aos fornos de cimentos, mas usualmente os mais pastosos são tratados em unidades especiais que, para além de controlarem a sua composição física e química para verificar se obedecem às normais legais e não prejudicam as operaçōes de fabrico do cimento, produzem misturas com serradura finas e homogeneizaçōes de blending que tornam a admissão e a combustão no forno mais fáceis e estáveis. Os resíduos sólidos, por exemplo pneus usados, são estraçalhados e cortados aos pedaços para facilitar a combustão uniforme no forno. As farinhas tem de ser desengorduradas a cerca de $12 \%$ para fluirem bem até aos fornos

\section{Referências}

${ }^{1}$ Sobre a queima não-controlada de resíduos e madeiras ver J. Cavalheiro, Queima de Residuos, www.incineracao.online.pt.

${ }^{2} \mathrm{G}$. H. Eduljee, Environment Resources Management, UK, comunicação pessoal.

${ }^{3}$ D. Gee (coordenador), M. Krzyzanowski e D. Gee (autores), "Human Health Issues", em Environment in the European Union at the Turn Of the Century, Cap. 3.10, European Environment Agency, Copenhague, 1999.

${ }^{4}$ P. G. Meozi. (coordenador) e E. Falck (autor), "Dispersion of Hazardous Substances", em Environment in the European Union at the Turn Of the Century, Cap. 3.3, European Environment Agency, Copenhague, 1999.

${ }^{5} \mathrm{MRC}, I E H$ Report on health effects of waste combustion products, Medical Research Council, Institute for Environment and Health, University of Leicester, Report R7, 1997.

${ }^{6} \mathrm{~A}$ distinção entre residuos banais e residuos perigosos diz respeito ao seu abandono no ambiente. Dentro dos fornos não há distinção entre resíduos perigosos e resíduos banais.

'USEPA, Final Technical Suport Document for HWC MACT Standards (vol. III); Selection of MACT Standard and Technologies, US Environment Protection Agency, 1999.
${ }^{8}$ Ver referências apresentadas em S. Formo sinho, C. Pio, H. Barros e J. Cavalheiro, Parecer relativo ao Tratamento de Residuos Industriais Perigosos. Vol. 1, Principia, Lisboa, Maio 2000, cap. 4. Ver ainda C. Pio, Oleos Usados e C. Pio, O que fazer com solventes contaminados? Reciclagem ou co-incineração em cimenteiras, em www.incineracao.online.pt.

${ }^{9}$ A. Azkona (coordenador), K. M. Christiansen, J. Riemer e C. Fischer (autores), "Waste Generation and management" em Environment in the European Union at the Turn Of the Century, Cap. 3.7, European Environment Agency, Copenhague, 1999

${ }^{10} \mathrm{~J}$. Zeevalkink, P. Eggels e W. F. Hesseling, Waste processing in a wet-cement kiln and a specialized combustion plant. Comparison of environmental impacts. Report TNO-MEP-R 96/082. TNO Institute of Environmental Sciences, Energy and Process Innovation, Holanda, 1996; J. P. Degré, "Obourg Cement Waste Co-combustion, em Proceedings of the Workshop on Co-incineration, H. Lamgenkamp e A. Marcolino (Eds.), págs. 92104, Joint Research Centre, Europeam Comission, EUR 18068 EN, 1998; ver também ref. 8, pág. 198 .

${ }^{11}$ S. Formosinho, C. Pio, H. Barros e J. CavaIheiro, Parecer relativo ao Tratamento de Residuos Industriais Perigosos. Vol. 1, Principia, Lisboa, Maio 2000, pág. 252
${ }^{12} \mathrm{~S}$. Punkte e M. Schneider, "The behaviour of metals in cement and concrete", ZKG International, 54, 106-113 (2001).

${ }^{13}$ S. Formosinho, C. Pio, H. Barros e J. CavaIheiro, Parecer relativo ao Tratamento de Residuos Industriais Perigosos. Vol. II, Principia, Lisboa, Dezembro 2000, pág. 72

${ }^{14}$ B. Dellinger, P. H. Taylor e C.C. Lee, "Development of Hazardous Waste Incinerability Surrogate Mixtures", Second Annual National Symposium on Incineration of Industrial Wastes, San Diego, 9-11Março, 1988; P. H. Taylor, B. Dellinger e C.C. Lee, "Development of a Thermal Stability Based Ranking of Hazordous Organic Compound Incinerability, Environment Science and Technology, 24, 316 (1990).

${ }^{15}$ S. J. Formosinho e L. G. Arnaut, Cinética Química. Relaçōes entre Reactividade Quimica e Estrutura Molecular, Imprensa na Universidade de Coimbra, no prelo.

${ }^{16}$ The Use of Industrial Waste as Alternative Fuels in the Cement Industry, Institute for the Diversification and Saving of Energy, DIS1289-97-ES, "New solutions in energy utilization", European Commission, Espanha, 2000. 


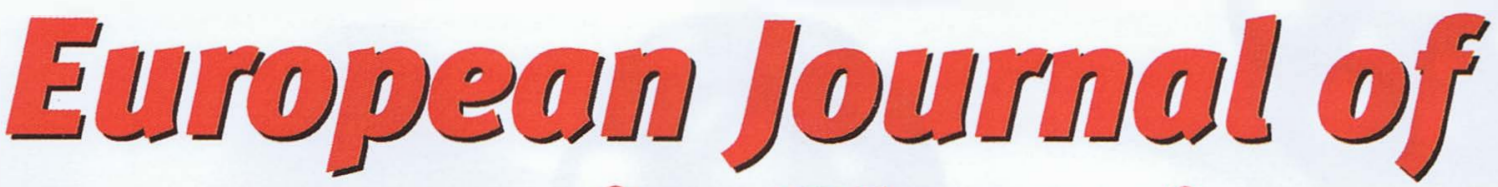

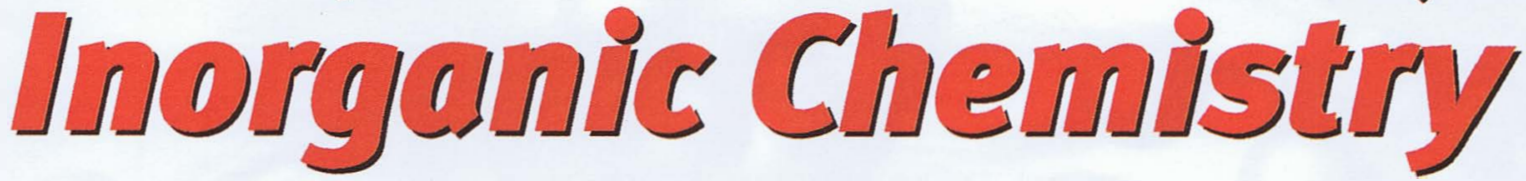

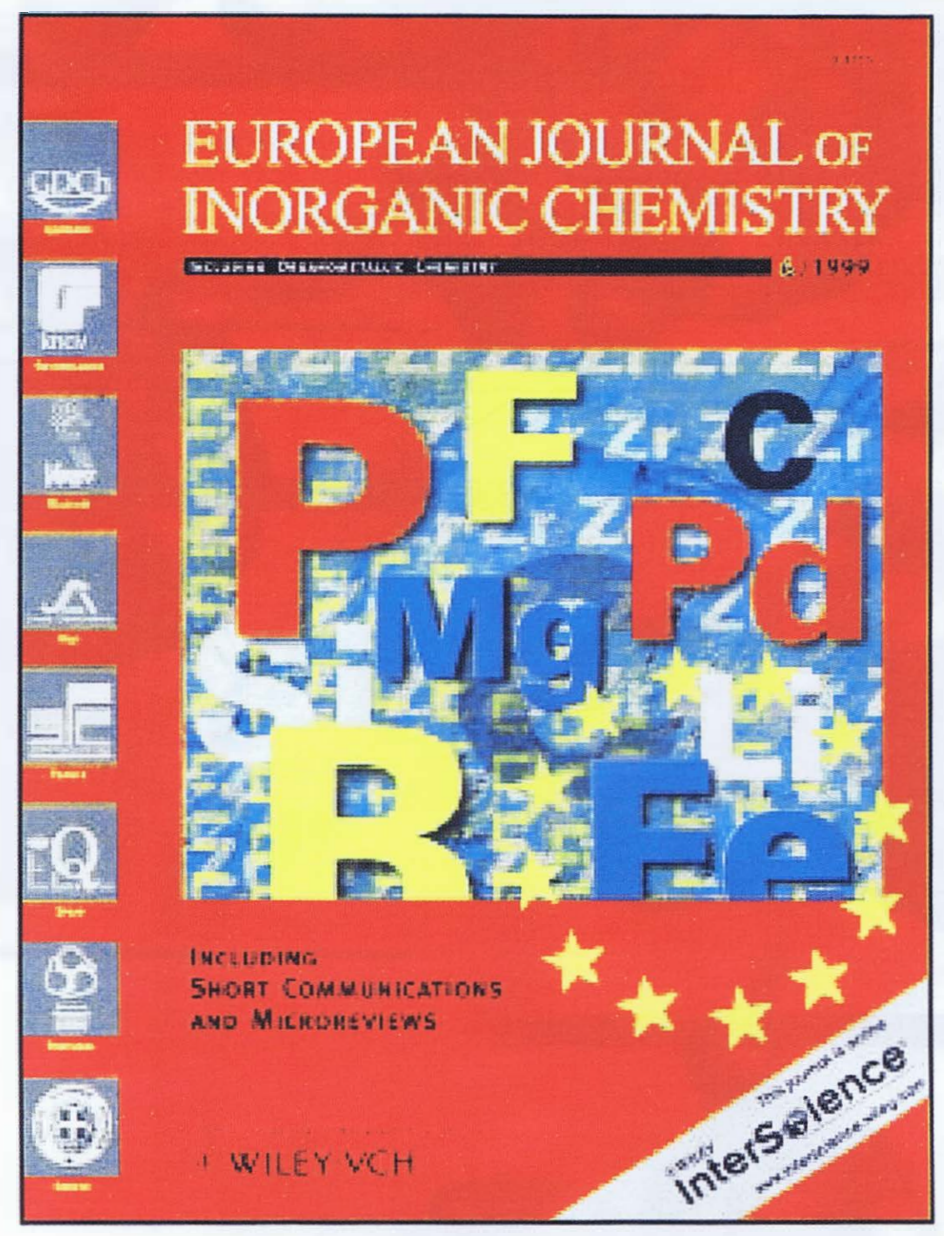

Benefit from:

.... Full-text available online for subscribers

(www.interscience.wiley.com)

.... strong international coverage

.... faster publication times:

articles available online weeks before print edition

.... cutting-edge research and information

.... low personal subscription rate for members of supporting societies

\section{$12 \%$ more pages planned for 2000}

supported and owned by Chemical Societies from $B \bullet D \bullet E \bullet F \bullet G R \bullet I \bullet N L \bullet P$

To order please contact your society orEJIC-EJOC@wiley-vch.de 


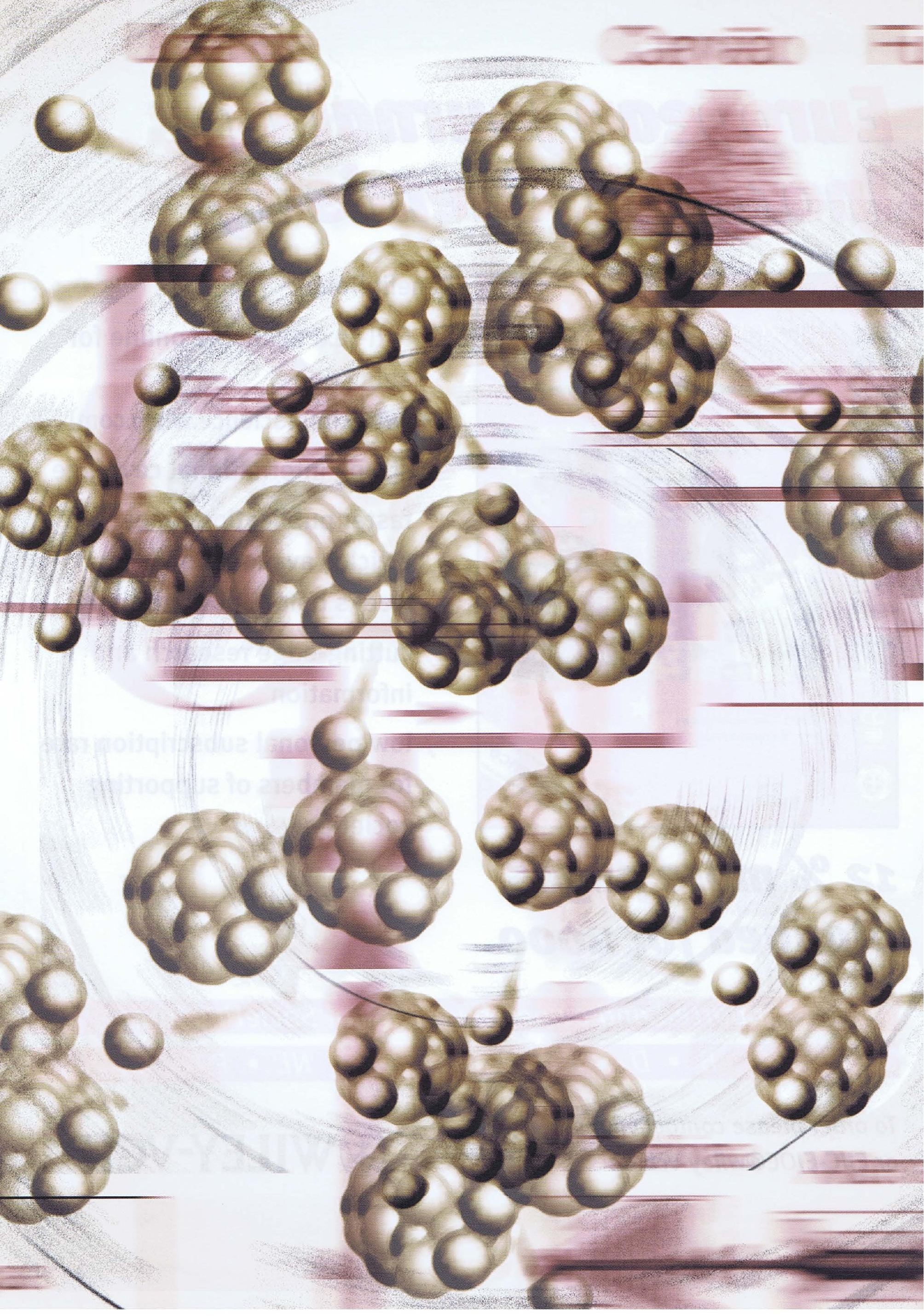

